\title{
Mechanism of the Inhibitory Action of Chestnut Astringent Skin Extract on Carbohydrate Absorption
}

\author{
Takahiro TSUITA and Takeshi TAKAKU \\ Bioscience, Integrated Center for Sciences, Ehime University, Shitsukawa, \\ Toon, Ehime 791-0295, Japan \\ (Received April 22, 2008)
}

\begin{abstract}
Summary Chestnut astringent skin (CAS) extract inhibited pancreatic $\alpha$-amylase and intestinal $\alpha$-glucosidase in a concentration-dependent manner with the $50 \%$ inhibition concentration $\left(\mathrm{IC}_{50}\right.$ ) for amylase, maltase and sucrase being 7.5, 650 and $390 \mu \mathrm{g} / \mathrm{mL}$, respectively. We have investigated the effect of CAS extract on carbohydrate absorption in normal rats. Oral administration of CAS extract to rats fed cornstarch $(2 \mathrm{~g} / \mathrm{kg}$ body weight $)$ significantly suppressed the increase of blood glucose levels and the area under the curve (AUC). Administration of CAS extract to rats fed maltose or sucrose delayed the increase of blood glucose level and slightly suppressed AUC, but not significantly. Administration of CAS extract to rats fed glucose did not affect the increase in blood glucose level or AUC. Similar results were observed with type- 2 diabetic model rats (GK/jcl). To test the effect of CAS extract on diabetes, type 2 diabetic model mice $(d b / d b$ mice) were fed a standard laboratory diet containing 1 or $2 \%$ CAS extract. CAS extract prevented increases in body weight and fasting blood glucose concentration. These data suggest that CAS extract has an anti-diabetic function in type 2 diabetic mice that mainly functions through inhibition of $\alpha$-amylase.
\end{abstract}

Key Words chestnut astringent skin, amylase inhibitor, blood glucose, oral carbohydrate tolerance test, $d b / d b$ mice

In mammals, dietary carbohydrate digestion is mediated by digestive enzymes such as amylase and $\alpha$-glucosidase. $\alpha$-Amylase is a key enzyme in dietary carbohydrate absorption catalyzing the first step in carbohydrate digestion by hydrolyzing the $\alpha-1,4$ glucoside linkages of polysaccharides such as starch (transforming starch to oligosaccharides). The oligosaccharides are further hydrolyzed by $\alpha$-glucosidases such as maltase and sucrase, which are located in the brush-border surface membrane of intestinal cells. Maltase hydrolyzes maltose and sucrase hydrolyzes sucrose. After these steps the resulting product, glucose, is absorbed into the small intestine and the blood glucose concentration increases. If these enzymes are inhibited, dietary carbohydrate absorption is also inhibited and the subsequent increase in blood glucose concentration is inhibited. Thus, many inhibitors of carbohydrate digestion enzymes have been marketed for the regulation of blood glucose concentration, for example, acarbose, voglibose and 0.19 wheat protein (1-4). Acarbose and voglibose are strong $\alpha$-glucosidase inhibitors and typical therapeutic agents used to control post-prandial glucose concentration and are thus used in treatment of type 2 diabetes $(5,6)$. The wheat protein is a homodimer of $26.6 \mathrm{kDa}$ and is an amylase inhibitor $(7,8)$, and is used

E-mail: tsujita@m.ehime-u.ac.jp

Abbreviations: AUC, area under the curve; CAS, chestnut astringent skin; $\mathrm{IC}_{50}, 50 \%$ inhibition concentration. as a functional food to both prevent and treat diabetes.

We previously reported that chestnut astringent skin (CAS) extract was a strong inhibitor of $\alpha$-amylase and reported that it could attenuate the rapid increase in blood glucose following consumption of a carbohydrate-containing meal by delaying or blocking absorption of carbohydrate (9). We also suggested that an active component(s) of the CAS extract might be a polyphenol. In this study, we have examined the mechanism of the inhibitory action of CAS extract on carbohydrate absorption. We have also examined the effect of CAS extract on diabetes in $d b / d b$ mice.

\section{MATERIALS AND METHODS}

Materials. CAS was obtained form Chuon Co. Ltd. (Matsuyama , Japan) and extracted with aqueous ethanol. One hundred grams of CAS were added to $200 \mathrm{~mL}$ of $75 \%$ aqueous ethanol, followed by stirring at $37^{\circ} \mathrm{C}$ for $12 \mathrm{~h}$. The mixture was filtered and the filtrate concentrated and lyophilized. $\alpha$-Amylase from porcine pancreas was obtained from Sigma-Aldrich Japan (Tokyo, Japan). An enzyme solution of $\alpha$-glucosidases was prepared from rat small intestine $(10,11)$.

Enzyme assay methods. $\alpha$-Amylase activity was determined by measuring the reducing power of released oligosaccharide from soluble starch by the method of Miller (12) with minor modifications (9). Maltase and sucrase activities were determined using maltose and sucrose as substrates, and the glucose pro- 

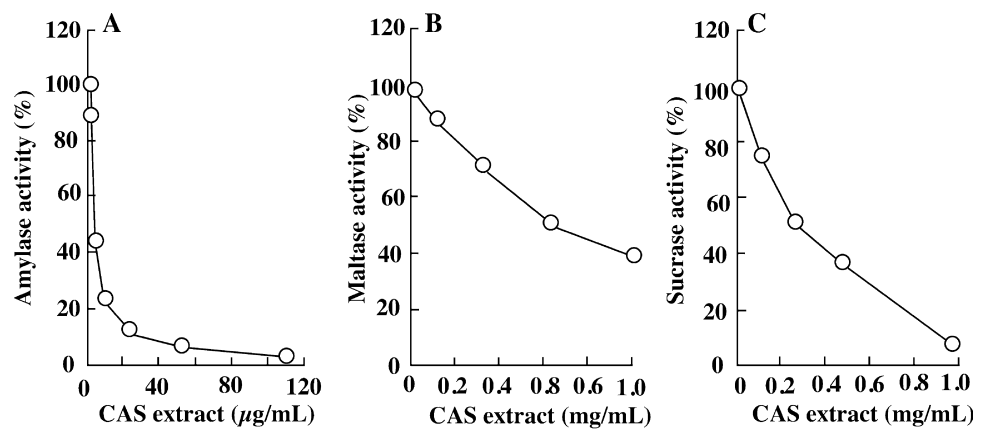

Fig. 1. Effect of increasing concentration of CAS extract on amylase (A), maltase (B) and sucrase (C) activities.

duced in the reaction was measured with a commercial assay kit (Glucose C II-test, Wako Pure Chemical Industries, Ltd., Osaka, Japan) $(10,11)$.

Oral carbohydrate tolerance test in rats. The experimental animal protocol was approved by the Animal Study Committee of Ehime University. Male jcl: Wistar rats (150 g, 6 wk old) were obtained from CLEA Japan, Inc. (Tokyo, Japan) and housed in a temperature $\left(23^{\circ} \mathrm{C}\right)$ - and humidity $(60 \%)$-controlled room set to a 12/12 h light/dark cycle. After the animals were given a standard laboratory diet (MF, Oriental Yeast Co., Ltd., Osaka, Japan) and water ad libitum for $1 \mathrm{wk}$, they were starved overnight $(15 \mathrm{~h})$ and divided into two groups. The test group received $2 \mathrm{~mL}$ of carbohydrate solution ( $2 \mathrm{~g} / \mathrm{kg}$ body weight) containing $1 \mathrm{~mL}$ of CAS extract powder solution while the control group received carbohydrate solution and $1 \mathrm{~mL}$ of water. After administration, blood samples were collected from the tail vein or artery at regular intervals. Blood glucose was measured using a blood glucose test meter, GLUCOCARD (Arkray Inc., Kyoto, Japan). After a 1-wk interval, the test and control groups were switched and the experiment was repeated. Type 2 diabetic model rats (mail GK/jcl, $300 \mathrm{~g}, 14 \mathrm{wk}$ ) were obtained from CLEA Japan, Inc. After $1 \mathrm{wk}$ feeding a standard laboratory diet, they were starved overnight (15 h), and subjected to the carbohydrate tolerance test as described above.

Effect of CAS extract on type II diabetic model mice. Type 2 diabetic model mice (male + Lepr $^{d b}$ / $+\operatorname{Lepr}^{d b} / \mathrm{Jcl}, d b / d b$ mice, $6 \mathrm{wk}$ old) were obtained from CLEA Japan, Inc. and housed in a temperature $\left(23^{\circ} \mathrm{C}\right)$ and humidity (60\%)-controlled room set to a $12 \mathrm{~h} / 12 \mathrm{~h}$ light/dark cycle. After the animals were given a standard laboratory diet (MF, Oriental Yeast Co., Ltd.) and water ad libitum for $1 \mathrm{wk}$, they were divided into three groups matched for body weight (each $n=10$ ). One group, the control diet group, was fed the standard laboratory diet (water $7.7 \%$, protein $23.6 \%$, fat $5.3 \%$, ash $6.1 \%$, dietary fiber $2.9 \%$, soluble non-nitrogen compound $54.4 \%, 360 \mathrm{kcal} / 100 \mathrm{~g}$ ) The other two groups, the CAS extract groups, were fed the standard laboratory diet containing different amounts of CAS extract (1 and $2 \%$ ). They were given free access to food and water, and body weight gain and food consumption were measured weekly. For determination of fasting blood glucose concentration, mice were starved overnight (15 h) and blood samples were collected from the tail vein or artery. Blood glucose was measured using a blood glucose test meter. The experiments were performed at 1wk intervals. After $8 \mathrm{wk}$ of feeding on the indicated diet, blood and tissues were collected. Plasma and liver lipids were measured as described previously (13).

Statistical analysis. Results are expressed as the mean \pm SE. The statistical significance of differences with and without (control) CAS extract was assessed using Student's $t$-test.

\section{RESULTS}

CAS extract powder is a dark brown powder containing $25.7 \%$ polyphenolic material (9) which inhibits $\alpha$ amylase and intestinal $\alpha$-glucosidase activities in a concentration-dependent manner (Fig. 1). A concentration of $7.5 \mu \mathrm{g} / \mathrm{mL}$ was determined to result in $50 \%$ inhibition of $\alpha$-amylase. However, the $\mathrm{IC}_{50}$ values of CAS extract for $\alpha$-glucosidase were 50 to 80 times higher than that for $\alpha$-amylase: 650 and $340 \mu \mathrm{g} / \mathrm{mL}$ towards maltase and sucrase activity, respectively. The $\mathrm{IC}_{50}$ values of CAS extract powder for $\alpha$-amylase did not change at $40^{\circ} \mathrm{C}$ for 6 mo (data not shown). The $\mathrm{IC}_{50}$ value of CAS extract also did not change when CAS extract water suspension $(10 \mathrm{mg} / \mathrm{mL})$ was incubated at $100^{\circ} \mathrm{C}$ for $1 \mathrm{~h}$. However, the $\mathrm{IC}_{50}$ value of CAS extract suspension was increased about 2.8-times by incubation at $120^{\circ} \mathrm{C}$ for $30 \mathrm{~min}$.

We examined whether the enzyme inhibition by CAS extract observed in vitro could exert an inhibitory effect on carbohydrate absorption in vivo. In normal rats blood glucose levels increased from a baseline of $47.6 \pm 1.84 \mathrm{mg} / \mathrm{dL}$ at $0 \mathrm{~min}$ to a peak of $95.9 \pm 2.30$ $\mathrm{mg} / \mathrm{dL}$ (increased blood glucose value $49.3 \pm 3.09 \mathrm{mg} /$ $\mathrm{dL})$ at $60 \mathrm{~min}$ after starch administration $(2 \mathrm{~g} / \mathrm{kg}$ body weight). The rise in blood glucose was suppressed significantly when CAS extract (100 mg/kg body weight) was given with starch (Fig. 2A-1). The area under the curve $\left(\mathrm{AUC}_{0-180 \mathrm{~min}}\right)$ was calculated geometrically, accounting only for area under the curve of incremental blood glucose level up to $180 \mathrm{~min}$. $\mathrm{AUC}_{0-180 \mathrm{~min}}$ for CAS extract administration was also found to decrease significantly compared to administration of starch alone (Fig. 2A-2). Figure 2B shows maltose administration. In normal rats blood glucose levels increased from a baseline of $46.7 \pm 2.14 \mathrm{mg} / \mathrm{dL}$ at $0 \mathrm{~min}$ to a peak of 

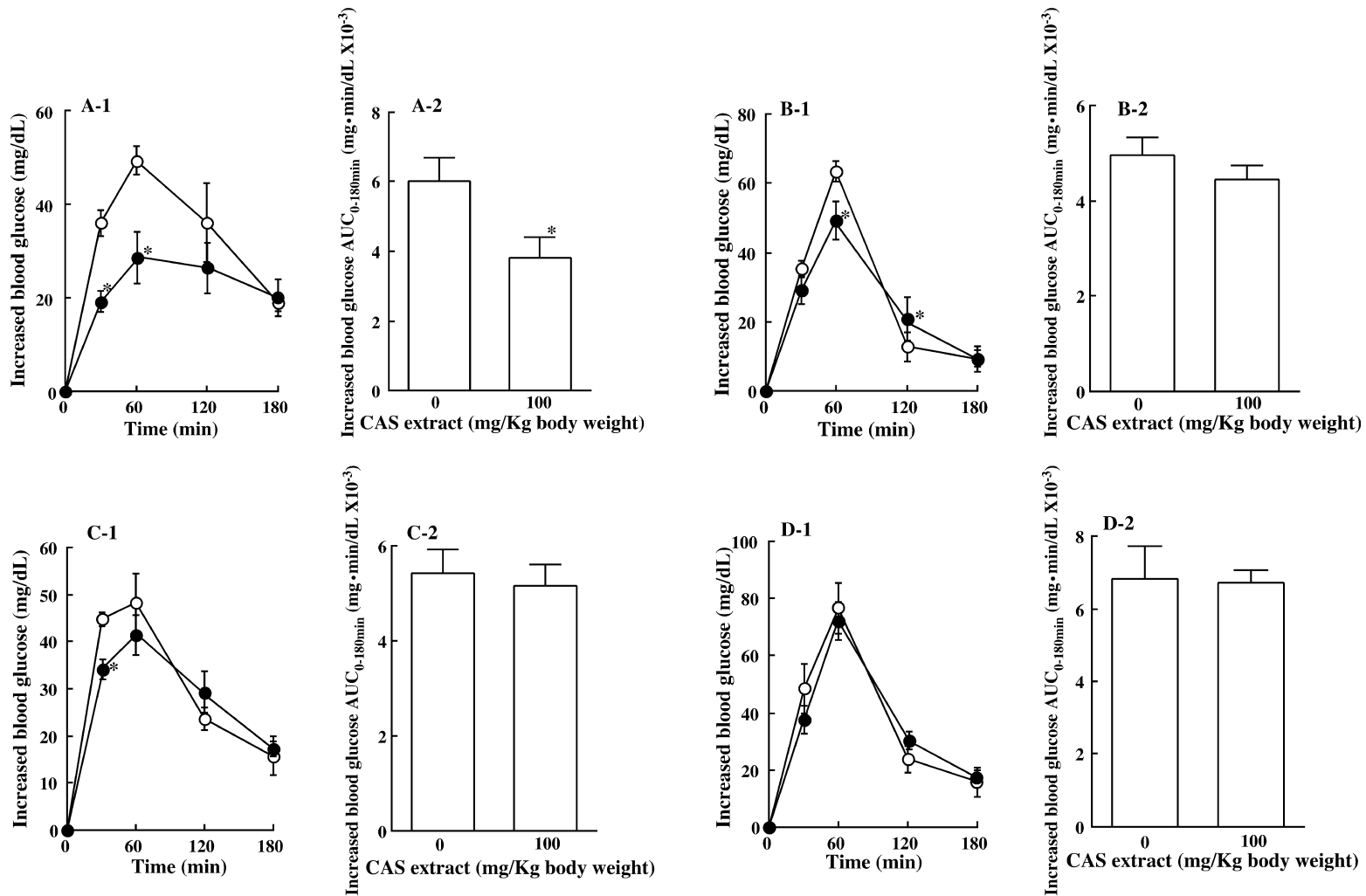

Fig. 2. Effect of CAS extract on blood glucose concentration (A-1, B-1, C-1 and D-1) and AUC $0-180 \min (\mathrm{A}-2$, B-2, C-2 and D-2) in normal rats. Rats were fasted for $15 \mathrm{~h}$ and CAS extract ( $100 \mathrm{mg} / \mathrm{kg}$ body weight, $\bullet$ ) and starch (A), maltose (B), sucrose $(\mathrm{C})$ or glucose (D) were administered at $2 \mathrm{~g} / \mathrm{kg}$ body weight. As a control $(\bigcirc)$, rats were given carbohydrate and water. The results are expressed as means \pm SE, $n=6,{ }^{*} p<0.05$ vs. control.
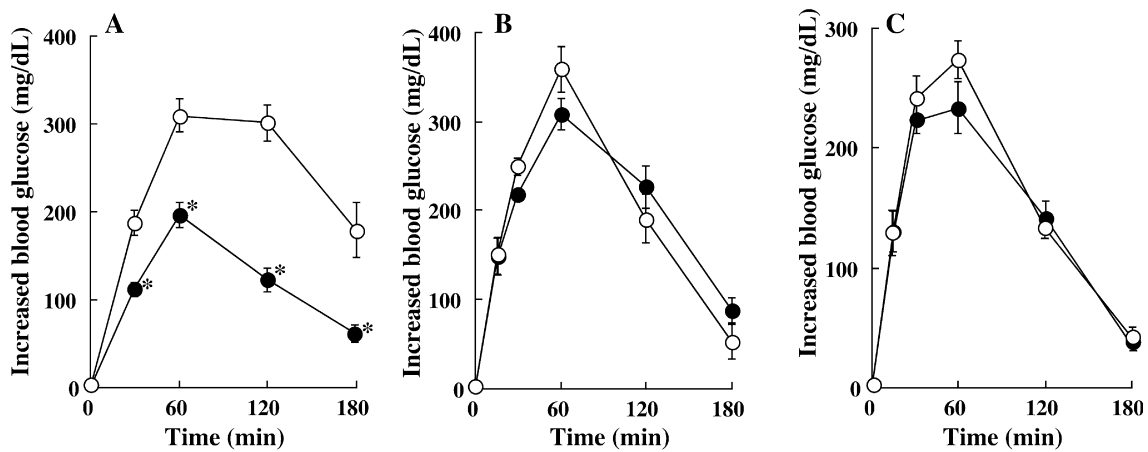

Fig. 3. Effect of CAS extract on blood glucose concentration in diabetic rats (GK/jcl). Rats were fasted for $15 \mathrm{~h}$ and $\mathrm{CAS}$ extract $(300 \mathrm{mg} / \mathrm{kg}$ body weigh, - ) and starch (A), maltose (B) or glucose (C) were administered at $2 \mathrm{~g} / \mathrm{kg}$ body weight. As a control $(\bigcirc)$, rats were given carbohydrate and water. The results are expressed as means \pm SE, $n=8,{ }^{*} p<0.05$ vs. control.

$110.3 \pm 4.09 \mathrm{mg} / \mathrm{dL}$ (increased blood glucose value $63.6 \pm 2.96 \mathrm{mg} / \mathrm{dL})$ at $60 \mathrm{~min}$ after maltose administration $(2 \mathrm{~g} / \mathrm{kg}$ body weight). At $60 \mathrm{~min}$ the rise in blood glucose was significantly suppressed when CAS extract (100 mg/kg body weight) was given with maltose while the level was significantly increased at $120 \mathrm{~min}$ (Fig. 2B-1). $\mathrm{AUC}_{0-180 \mathrm{~min}}$ for CAS extract administration was slightly decreased, but not significantly, compared to administration of maltose alone (Fig. 2B-2). Similar results were observed with sucrose administration (Fig. 2C). Blood glucose levels increased from a baseline of $53.5 \pm 2.78 \mathrm{mg} / \mathrm{dL}$ at $0 \mathrm{~min}$ to a peak of $101.8 \pm 3.70$ $\mathrm{mg} / \mathrm{dL}$ (increased blood glucose value $48.3 \pm 6.12 \mathrm{mg} /$ $\mathrm{dL})$ at $60 \mathrm{~min}$ after sucrose administration $(2 \mathrm{~g} / \mathrm{kg}$ body weight). The rise in blood glucose was suppressed at $60 \mathrm{~min}$ when CAS extract $(100 \mathrm{mg} / \mathrm{kg}$ body weight) was given while the level was increased at $120 \mathrm{~min}$ (Fig. 2C-1). $\mathrm{AUC}_{0-180 \text { min }}$ for CAS extract administration was slightly decreased, but not significantly compared to administration of sucrose alone (Fig. 2C-2). The rise in blood glucose and $\mathrm{AUC}_{0-180 \mathrm{~min}}$ after glucose administration ( $2 \mathrm{~g} / \mathrm{kg}$ body weight) was unaffected by administration of CAS extract (Fig. 2D). Similar results were observed in the type-2 diabetic model rats (GK/jcl) (Fig. $3)$. Fasting blood glucose levels in diabetic model rats were high $96 \pm 8.1 \mathrm{mg} / \mathrm{dL}$ and blood glucose levels increased to a peak of $406 \pm 19.4 \mathrm{mg} / \mathrm{dL}$ (increased blood glucose value $309 \pm 18.1 \mathrm{mg} / \mathrm{dL}$ ) at $60 \mathrm{~min}$ after 

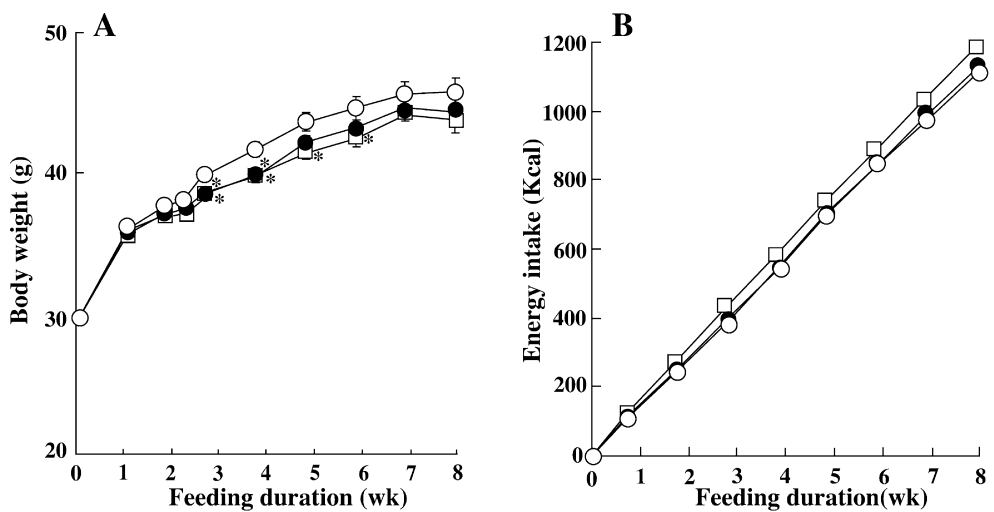

Fig. 4. Effect of CAS extract on body weight (A) and energy intake (B) in type 2 diabetic model mice ( $d b / d b$ mice). Each point represents the means \pm SE of 10 mice. ${ }^{*} p<0.05$ vs. control. Each symbol represents the following: standard diet (control, $\bigcirc$ ), standard diet plus $1 \%$ CAS extract

(•) and standard diet plus $2 \%$ CAS extract $(\square)$.

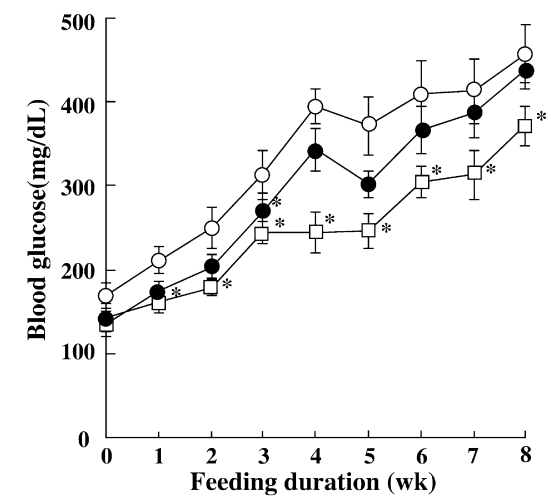

Fig. 5. Effect of CAS extract on fasting blood glucose levels in type 2 diabetic model mice $(d b / d b$ mice). Each point represents the means \pm SE of 10 mice. ${ }^{*} p<0.05$ vs. control. Each symbol represents the following: standard diet (control, O), standard diet plus 1\% CAS extract $(\bullet)$ and standard diet plus $2 \%$ CAS extract $(\square)$.

starch administration ( $2 \mathrm{~g} / \mathrm{kg}$ body weight). The rise in blood glucose was suppressed significantly when CAS extract (300 mg/kg body weight) was given with starch (Fig. 3A). $\mathrm{AUC}_{0-180 \text { min }}$ for CAS extract administration was found to decrease significantly compared to that with administration of starch alone (data not shown). With maltose administration ( $2 \mathrm{~g} / \mathrm{kg}$ body weight), blood glucose levels increased from a baseline of $99.8 \pm 6.7 \mathrm{mg} / \mathrm{dL}$ at $0 \mathrm{~min}$ to a peak of $459 \pm 27.9 \mathrm{mg} /$ $\mathrm{dL}$ (increased blood glucose value $359 \pm 24.9 \mathrm{mg} / \mathrm{dL}$ ) at $60 \mathrm{~min}$. At $60 \mathrm{~min}$ the rise in blood glucose was suppressed when CAS extract (300 $\mathrm{mg} / \mathrm{kg}$ body weight) was given with maltose while the level was significantly increased at $120 \mathrm{~min}$ (Fig. 3B). The rise in blood glucose however was not much changed after glucose administration ( $2 \mathrm{~g} / \mathrm{kg}$ body weight) upon inclusion of CAS (Fig. 3C).

We examined the effect of CAS extract on body weight and fasting blood glucose levels in type 2 diabetic model mice ( $d b / d b$ mice). The results show that CAS extract suppressed increases in body weight (Fig. 4A). The diet containing $2 \%$ CAS extract significantly suppressed the body weight during weeks 3 to 6 of the experimental period and the 1\% CAS extract diet also suppressed the body weight at the 3rd week of the experimental period. The energy intake per mouse did not differ much during the whole experimental period regardless of whether CAS was included in the diet (Fig $4 \mathrm{~B})$. The fasting blood glucose concentration of $d b / d b$ mice was high $(150 \pm 9.1 \mathrm{mg} / \mathrm{dL})$ when the experiment began ( 7 wk of age), and increased to $457 \pm 34.2 \mathrm{mg} / \mathrm{dL}$ $8 \mathrm{wk}$ into the experimental period ( $15 \mathrm{wk}$ of age). CAS extract concentration-dependently lowered the fasting blood glucose level compared to the control group (Fig. 5 ). The $2 \%$ CAS extract diet significantly lowered the fasting blood glucose level over the whole experimental period. The CAS extract diet (2\%) also significantly suppressed the wet weight of epididymal adipose tissue compared to the control group (control: $2.30 \pm 0.09 \mathrm{~g}$, $1 \%$ CAS extract: $2.23 \pm 0.10 \mathrm{~g}, 2 \%$ CAS extract: $2.05 \pm$ $0.07 \mathrm{~g})$. Liver weight and plasma lipid concentration were similar for diets with and without CAS extract (data not shown). Liver lipid concentrations were also similar for diets both with and without CAS extract (data not shown).

\section{DISCUSSION}

Chestnut is a deciduous timber tree of the genus Castanea, in the beech family and is cultivated over a large area of Japan. We examined the effect of chestnut extracts on $\alpha$-amylase activity. Chestnut parts such as bark, leaf, bur-spine, shell and astringent skin were extracted with ethanol-containing water and the amylase inhibitory activities assayed. All extracts inhibited the $\alpha$-amylase activity (data not shown). In particular, shell and astringent skin extract strongly inhibited $\alpha$ amylase activity. Shell and astringent skin of chestnut are generated in large quantities as waste products during astringent skin-free nut processing. Astringent skin is recognized as an edible fraction but shell is not. Therefore, we used astringent skin as a candidate safe and inexpensive functional food material.

Diabetes is a disease in which the amount of blood glucose is too high because the body cannot use glucose 
properly. There are two main types of diabetes, Type 1 and Type 2. Type 1 diabetes is insulin dependent with patients unable to produce insulin. Type 2 diabetes is non-insulin dependent with patients able to make some insulin, but where cells become resistant to insulin. Diabetes is a major worldwide public health problem with the number of patients increasing greatly in the last $50 \mathrm{y}$ in both developed and developing nations (14). In Japan, about 8.2 million people are diabetic patients and about 10.5 million people are pre-diabetic patients (from the actual conditional report of 2006 from the Ministry of Health, Labor and Welfare of Japan). For diabetic patients, maintenance of healthy blood glucose levels is important and blood glucose concentration is greatly affected by dietary carbohydrates. Recent studies suggest that postprandial hyperglycemia is an important contributing factor to the development of atherosclerosis and cardiovascular disease (15-17). Postprandial hyperglycemia induces adhesion molecules and coagulation factors in vascular wall cells via oxidative stress generation and is thus involved in the pathogenesis of endothelial dysfunction and atherosclerosis. Therefore, control of postprandial plasma glucose levels is important and various $\alpha$-glucosidase or $\alpha$-amylase inhibitors have been used to inhibit excess energy supply, to control blood glucose levels and to prevent or treat obesity and diabetes (18-20). Previously, we reported that CAS extract retarded absorption of carbohydrate and reduced postprandial hyperglycemia in rats and humans (9).

In vitro, CAS extract strongly inhibits $\alpha$-amylase activity, with the $\mathrm{IC}_{50}$ value for $\alpha$-amylase being about 50 to 80 times lower than that for $\alpha$-glucosidases such as maltase and sucrase (Fig. 1). These results were reflected in the in vivo results (Figs. 2 and 3). Thus, CAS extract significantly suppressed the rise in blood glucose level and total carbohydrate absorption after starch administration. Upon administration of maltose or sucrose, although CAS extract delayed the rise in blood glucose level it did not suppress total carbohydrate absorption. Furthermore, CAS extract did not affect the rise in blood glucose level or total carbohydrate absorption upon administration of glucose. These results suggest that the suppression of carbohydrate absorption by CAS extract mainly results from amylase inhibition.

The $d b / d b$ mouse is a mutant leptin receptor inbred strain maintained on a BL/ 6 background. It is a genetic model of type 2 diabetes that displays many of the characteristics of the human disease including hyperglycemia, insulin resistance and obesity (21-23). The body weight of $d b / d b$ mice increased upon overeating with animals reaching $45.8 \pm 0.98 \mathrm{~g}$ at $15 \mathrm{wk}$ of age, a value which is almost 1.5 -fold the weight of control mice (normal 57/BL mice, 29.1 $\pm 0.73 \mathrm{~g}$ ) (13). CAS extract prevented the increase in body weight and adipose tissue weight of mice without a decrease in the food intake (Fig. 4). CAS extract also prevented the increase in the fasting blood glucose level (Fig. 5). Previously we reported that CAS extract retarded absorption of carbohydrate and reduced postprandial hyperglycemia in dia- betic rats and humans (9). These results suggest that CAS extract exerts an anti-diabetic effect by inhibiting $\alpha$-amylase, retards carbohydrate absorption and reduces post-prandial hyperglycemia. Therefore, CAS extract is a strong candidate as an agent that inhibits carbohydrate absorption.

\section{Acknowledgments}

This work was supported by Japan Science and Technology Agency. This work also was supported by research grants from Rohto Pharmaceutical Co. Ltd. (Osaka, Japan) and Chuon Co. Ltd. (Matsuyama, Japan).

\section{REFERENCES}

1) Bischoff H. 1994. Pharmacology of alpha-glucosidase inhibition. Eur J Clin Invest 24: S3-S10.

2) Peterson RG. 1994. Alpha-glucosidase inhibition in diabetes: lessons from animal studies. Eur J Clin Invest 24: S11-S18.

3) Horii S, Fukase H, Matsuo T, Kameda Y, Asano N, Matsui K. 1986. Synthesis and alpha-D-glucosidase activity of N-substituted valioamine derivatives as potential oral antidiabetic agents. J Med Chem 29: 1038-1046.

4) Matsuo T, Odaka H, Ikeda H. 1992. Effect of an intestinal disaccharidase inhibitor (AO-128) on obesity and diabetes. Am J Clin Nutr 55: 314S-317S.

5) DeFronzo RA. 1999. Pharmacologic theraphy for type 2 diabetes mellitus. Ann Intern Med 131: 281-303.

6) Goto Y, Yamada K, Ohyama T, Matsuo T, Odaka H, Ikeda H. 1995. An alpha-glucosidase inhibitor, AO-128, retards carbohydrate absorption in rats and humans. Diabetes Res Clin Pract 28: 81-87.

7) O'Donnell MD, McGeeney KF. 1976. Purification and properties of an alpha-amylase inhibitor from wheat. Biochim Biophys Acta 422: 159-169.

8) Oneda H, Lee S, Inouye K. 2004. Inhibitory effect of 0.19 alpha-amylase inhibitor from wheat kernel on the activity of porcine pancreas alpha-amylase and its thermal stability. J Biochem 135: 421-427.

9) Tsujita T, Takaku T, Suzuki T. 2008. Chestnut astringent skin extract, an amylase inhibitor, retards carbohydrate absorption in rats and humans. J Nutr Sci Vitaminol 54: 82-88.

10) Kessler M, Acuto O, Storelli C, Murer H, Müler M, Semenza G. 1978. A modified procedure for the rapid preparation of efficiently transporting vesicles from small intestinal brush border membranes. Their use in investigating some properties of D-glucose and choline transport systems. Biochim Biophys Acta 506: 136154.

11) Dahlqvist A. 1964. Method for assay of intestinal disaccharidases. Anal Biochem 7: 18-25.

12) Miller GL. 1959. Use of dinitrosalicylic acid reagent for determination of reducing suger. Anal Chem 31: 426428.

13) Tsujita T, Takaichi H, Takaku T, Aoyama S, Hiraki J. 2006. Antiobesity action of epsilon-polylysine, a potent inhibitor of pancreatic lipase. J Lipid Res 47: 18521858.

14) Yoon KH, Lee JH, Kim JW, Cho JH, Ko SH, Zimmet P, Son HY. 2006. Epidemic obesity and type 2 diabetes in Asia. Lancet 368: 1681-1688.

15) Bonora E, Muggeo M. 2001. Postprandial blood glucose 
as a risk factor for cardiovascular disease in type II diabetes: the epidemiological evidence. Diabetologia 44: 2107-2114.

16) Ceriello A. 2005. Postprandial hyperglycemia and diabetes complications. Is it time to treat? Diabetes 54: 1-7.

17) Yamagishi SI, Nakamura K, Matsui T, Ueda SI, Imaizumi T. 2007. Role of postprandial hyperglycemia in cardiovascular disease in diabetes. Int J Clin Pract 61: 83-87.

18) Koukiekolo R, Le Berre-Anton V, Desseaux V, Moreau Y, Rouge P, Marchis-Mouren G, Santimone M. 1999. Mechanism of porcine pancreatic alpha-amylase inhibition of amylose and maltopentaose hydrolysis by kidney bean (Phaseolus vulgaris) inhibitor and comparison with that by acarbose. Eur J Biochem 265: 20-26.

19) Lankisch M, Layer P, Rizza RA, DiMagno EP. 1998.
Acute postprandial gastrointestinal and metabolic effects of wheat amylase inhibitor (WAI) in normal, obese and diabetic humans. Pancreas 17: 176-181.

20) Layer P, Zinsmeister AR, DiMagno EP. 1986. Effect of decreasing intraluminal amylase activity on starch digestion and postprandial gastrointestinal function in human. Gastroenterology 91: 41-48.

21) Hummel KP, Dickie MM, Coleman DL. 1966. Diabetes, a new mutation in the mouse. Science 153: 1127-1128.

22) Kobayashi K, Forte TM, Taniguchi S, Ishida BY, Oka K, Chan L. 2000. The $d b / d b$ mouse, a model for diabetic dyslipidemia: molecular characterization and effects of Western diet feeding. Metabolism 49: 22-31.

23) Coleman DL. 1978. Obese and diabetes: two mutant genes causing diabetes-obesity syndromes in mice. Diabetologia 14: 141-148. 